\title{
Effects of different periods of gastric ischemia on liver as a remote organ ${ }^{1}$
}

Maria Angélica Baron Magalhães', Andy Petroianu", Alfredo José Afonso Barbosa'", Juliano Alves Figueiredo'v , Luiz Ronaldo Albertiv, Jurandir Marcondes Ribas Filhovi

'DVM, PhD, Associate Professor, Department of Surgery, Faculty of Medicine, Universidade Federal de Minas Gerais (UFMG), Belo-Horizonte-MG, Brazil. Conception and design of the study; acquisition, analysis and interpretation of data; technical procedures; manuscript preparation and writing; critical revision.

"PhD, Full Professor, Department of Surgery, Faculty of Medicine, UFMG, Researcher 1B CNPq, Belo Horizonte-MG, Brazil. Conception and design of the study; acquisition, analysis and interpretation of data; critical revision, final approval.

I'PhD, Full Professor, Department of Pathology, Faculty of Medicine, UFMG, Belo Horizonte-MG, Brazil. Conception and design of the study, histopathological examinations, analysis and interpretation of data.

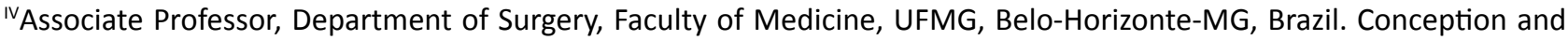
design of the study, technical procedures.

${ }^{V}$ Associate Professor, Department of Surgery, Faculty of Medicine, UFMG, Belo-Horizonte-MG, Brazil. Analysis and interpretation of data, statistics analysis.

V'Associate Professor, Department of Surgery, Faculty of Medicine, Faculdade Evangélica do Paraná (FEPAR), Curitiba-PR, Brazil. Conception and design of the study, critical revision.

\section{Abstract}

Purpose: To evaluate the hepatic changes associated with gastric ischemia.

Methods: Thirty male rabbits were studied, distributed in 3 groups $(n=10)$. Group 1: ligature and section of the gastric vasculature and removal of the liver after three hours; Group 2: ligature and section of the gastric vasculature and removal of the liver after 6 hours; Group 3: ligature and section of the gastric vasculature and removal of the liver after 12 hours. Blood samples were collected immediately before surgery and after the determined time of ischemia in each group to evaluate the hepatic function. After the death of the rabbits, the liver was removed for macro and microscopic study.

Results: An increase in aminotransferases and bilirubin occurred in groups 2 and 3. Total protein and albumin diminished in all of the animals. All of the rabbits from groups 2 and 3 presented hepatocellular necrosis.

Conclusion: The devascularization of the stomach for a period of above three hours is associated with hepatic morphological and functional disorders.

Key words: Stomach. Ischemia. Inflammation. Liver. Rabbits. 


\section{Introduction}

Gastric ischemia is caused by reduction or interruption of blood flow to the stomach, due to mechanical and functional factors. It may be a result of esophagogastroplasties and gastric resections, used in the treatment of esophageal cancer, megaesophagus and severe caustic esophagitis. The other is when the stomach is used in retrosternal position to preserve the digestive tube when an obstructed esophagus cannot be removed. In both instances, the vitality of the stomach is preserved only by right gastroepiploic vessels, the last branch and affluents of the gastroduodenal vessels ${ }^{1-4}$.

Gastric volvus is a common disorder in dogs. In some occasions a delayed surgical treatment may lead to complete vascular obstruction due to their torsion with consequent gastric necrosis. Besides, gastric ischemia may be a consequence of the desvascularization of the organ in the treatment of portal hypertension, and also after splenectomy surgeries, venous thrombosis and phlebitis, coagulopathies, sepsis and shock ${ }^{1-4}$.

This event is rarely diagnosed ${ }^{2}$, and if the gastric blood flow is not reestablished immediately, irreversible disorders can occur, culminating in a catastrophic complete gastric necrosis and systemic remote injuries. Gastric necrosis unleashes a local inflammatory process that can be associated with disturbances in other organs and systems ${ }^{2}$, giving rise to the systemic inflammatory response syndrome (SIRS) and multiple organ dysfunction syndrome (MODS), which affects vital organs such as liver.

The liver plays an important role in the defense of the organism during SIRS, and is responsible for the modulation of the inflammatory process, through filtering, as well as the inactivation and destruction of bacteria, endotoxins, vasoactive substances and other inflammatory mediators ${ }^{5}$. Once stimulated, the liver produces and releases a large quantity of cytotoxins, bioactive lipids, and acute-phase proteins, which promote hepatocellular lesions ${ }^{5}$. The etiopathogenesis of the liver morphological and functional disorders secondary to organ ischemia and SIRS continue to challenge scientific comprehension ${ }^{6-8}$. Gastric ischemia may occur in many clinical situations and liver injury may be a severe consequence that represents an important cause of death in critically ill patients.

In this way, the knowledge about liver engagement on conditions of gastric ischemia is important for the treatment, and, therefore, for the prognoses of these patients. Because of that, we aimed to investigate the repercussion of gastric ischemia on liver function and morphology, once it is an important event in Intensive Care Unit and, nevertheless, there is a lack of literature in this area.

This work seeks to verify if gastric ischemia does in fact have repercussions on hepatic morphology and functions.

\section{Methods}

This experiment was conducted according to the technical guidelines for animal experimentation, according to Brazilian Law 11.794, and was approved by the Research Ethics Committee in Animal Experimentation (CETEA) from the Universidade Federal de Minas Gerais (UFMG) under the Protocol nr. $007 / 2008$.

This experiment studied 30 white New Zealand male rabbits, weighing between $2.5 \mathrm{~kg}$ and $3.0 \mathrm{~kg}$. At the beginning of the procedure, $3 \mathrm{ml}$ of blood were collected from all of the animals, by auricular venous puncture. The hepatic functions were examined by means of alkaline phosphatase (ALP), alanine aminotransferase (ALT), aspartate aminotransferase (AST), gamaglutamiltranspeptidase (GGT), total proteins 
(TP), albumin, direct and indirect bilirubins. The rabbits were anesthetized with intramuscular 2\% xylazine hydrochloride, at a dose of $10 \mathrm{mg} / \mathrm{kg}$, associated with $10 \%$ ketamine hydrochloride, at a dose of $60 \mathrm{mg} /$ $\mathrm{kg}$. When necessary, one fourth of the initial dose of anesthesia was also applied. The same surgical procedure was performed on all of the animals. After median laparotomy, all of the perigastric arterial and venous blood vessels were ligated and sectioned. The abdominal cavity was closed and the rabbits were distributed randomly in three groups $(n=10)$ :

Group 1: animals submitted to gastric devascularization and removal of the liver after three hours;

Group 2: animals submitted to gastric devascularization and removal of the liver after six hours;

Group 3: animals submitted to gastric devascularization and removal of the liver after twelve hours. Immediately before removing the liver, a new blood sample was collected in the auricular vein for the same exams carried out before surgery.

No action was done to prevent or treat the gastric and hepatic injuries provoked by the gastric devascularization. The rabbits were operated on again under an overdose of ketamine $(100 \mathrm{mg} / \mathrm{kg})$. The abdominal cavity was reopened and the liver was removed. The livers were evaluated macroscopically and three fragments were collected for microscopy. After fixation in $10 \%$ formaldehyde, the fragments were processed according to the histological routine and stained with hematoxylin and eosin (HE). Only one pathologist performed all blinded hystological analises.

Data were reported as mean \pm standard error from the mean. Comparison among the biochemical exams was performed through analysis of variance (ANOVA), followed by the Tukey test after verifying its normal distribution by the Kolmogorov Smirnov test.
The comparison between the pre- and postoperative values for each group was carried out by the Student's t test. To compare the microscopic changes, the Fisher exact test was applied. All of the results were considered significant for a probability of above $95 \%$ $(p<0.05)$.

\section{- Results}

\section{Macro and microscopic analyses}

\section{Stomach}

Macroscopic examination of the stomach of all the animals in the three groups showed localized or diffuse changes indicative of hemorrhagic necrosis (Figures 1 and 2). The gastric fundus and body were most affected in all rabbits. In most animals the antral region was preserved, presenting only mild congestive changes of the mucosa in two animals each in groups 2 and 3 . All animals of groups 1, 2 and 3 presented macroscopic lesions indicative of hemorrhagic necrosis of varying extension in the body and fundus, of greater intensity in groups 2 and 3 ( 6 and $12 \mathrm{~h}$ ) compared to group 1 (3h).
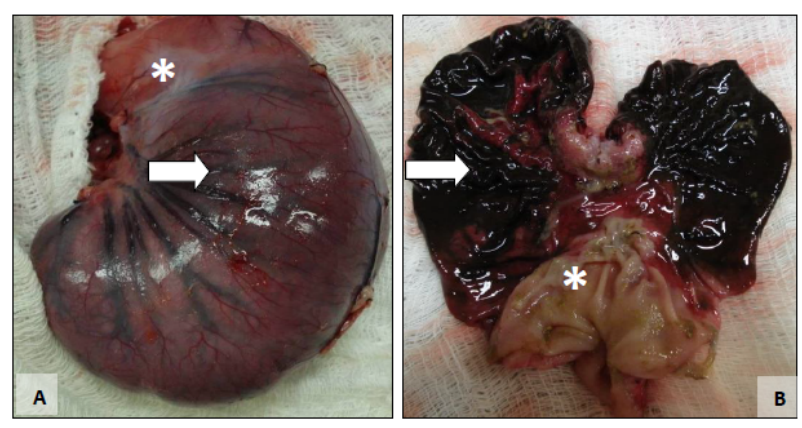

Figure 1 - Macroscopic aspect of the closed and opened stomach of the same rabbit after $6 \mathrm{~h}$ of gastric ischemia. A. Outer surface of the stomach with signs of hemorrhagic necrosis of the body region (arrow) while the antropyloric region $\left({ }^{*}\right)$ is preserved. B. Diffuse hemorrhagic necrosis in the body and fundus regions (arrow), while the antral region $\left({ }^{*}\right)$ is preserved. 


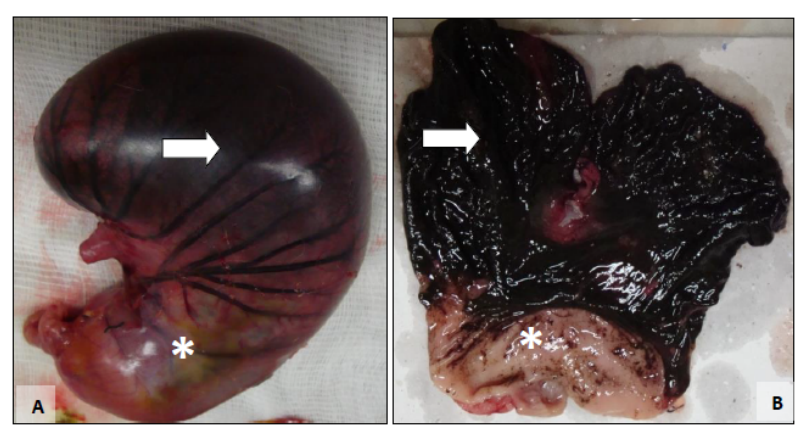

Figure 2 - Macroscopic aspect of the closed and opened stomach of the same rabbit after $12 \mathrm{~h}$ of gastric ischemia. A. Outer surface of the stomach with signs of hemorrhagic necrosis of the body and fundus (arrow) while the antropyloric region $\left({ }^{*}\right)$ is preserved. B. Diffuse and marked hemorrhagic necrosis of the gastric mucosa in the body and fundus regions (arrow), while the antral region $\left({ }^{*}\right)$ is preserved.

Microscopic changes in stomach tissues became more conspicuous with increasing time of gastric ischemia. Edema and vessel congestion were observed in the mucosa, submucosa and muscle layers of the three gastric regions in all animals. Areas of mucosal necrosis of the body and fundus occurred in all animals after three hours of gastric ischemia and only two animas in this group presented necrosis of the muscle layer in the region of the gastric fundus.

Necrosis of the mucosa of the antropyloric region was observed in only one rabbit each in groups 2 and 3, and the muscle layer of this region was preserved in all animals of the three groups. Hemorrhagic necrosis of the mucosa of the gastric body and fundus was observed in all animals of groups 2 (6h) and 3 (12h). Four animals developed necrosis of the muscle layer in the gastric body and fundus after $6 \mathrm{~h}$ of ischemia (group 2). After $12 \mathrm{~h}$ of ischemia (group 3), necrosis of the muscle layer was observed in the gastric body of six animals and in the fundus of four animals.

Liver

Yellowish and whitish areas were observed in the hepatic parenchymal of two animals from group 1, six from group 2 , and in all of the animals from group 3 (Figure 3 ).

The results obtained in the histological analysis are presented in Table 1 . A difference among the groups as regards the microscopic changes was observed $(p=0.0010)$. Extensive areas of vacuolar hydropic degeneration were found in all of the animals from groups 1 and 3 and in eight animals from group 2 (Figure $4 A)$. Dilatation and congestion of blood vessels were found in all of the animals from groups 1 and 3, and in eight animals from group 2. Hepatocellular necrosis occurred in two animals from group 1 and in all of the rabbits from groups 2 and 3 (Figure 4 A-B). Leukocyte infiltration with predominance of polymorphs was observed in eight animals from group 3 (Figure 4B).

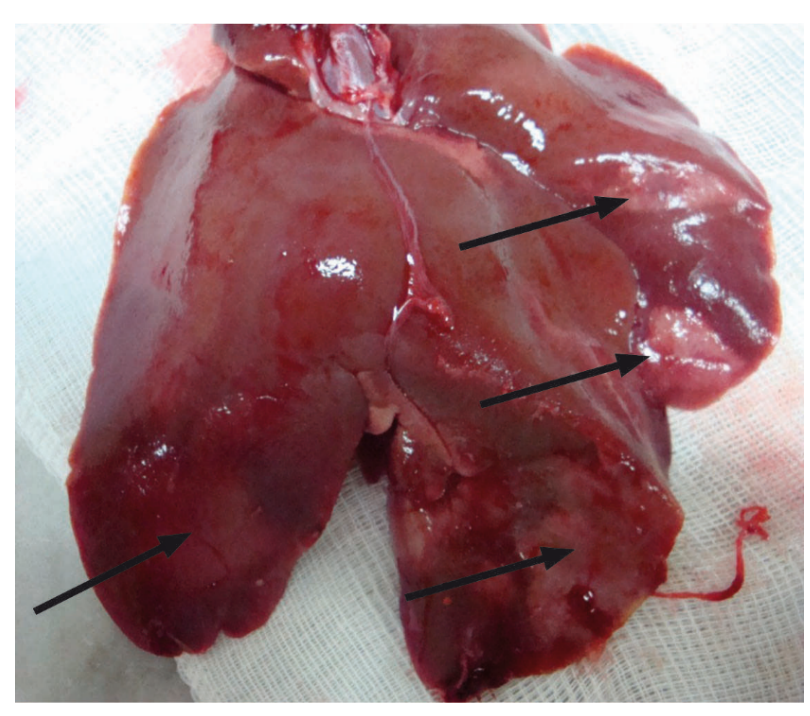

Figure 3-Macroscopic aspect of a rabbit liver from group 3, showing whitish blotches (arrows) in the hepatic parenchyma. 
Table 1 - Microscopic changes of liver in animals from Groups 1, 2 and 3, after determined periods of gastric ischemia.

\begin{tabular}{cccccc}
$\begin{array}{c}\text { GROUP/ } \\
\text { MICROSCOPIC } \\
\text { CHANGES }\end{array}$ & $\begin{array}{c}\text { VACUOLAR } \\
\text { HYDROPIC } \\
\text { DEGENERATION } \\
\mathbf{n}(\%)\end{array}$ & $\begin{array}{c}\text { DILATATION } \\
\text { OF BLOOD } \\
\text { VESSELS } \\
\mathbf{n}(\%)\end{array}$ & $\begin{array}{c}\text { CONGESTION OF } \\
\text { BLOOD VESSELS } \\
\mathbf{n}(\%)\end{array}$ & $\begin{array}{c}\text { HEPATOCELLULAR } \\
\text { NECROSIS } \\
\mathbf{n}(\%)\end{array}$ & $\begin{array}{c}\text { LEUKOCYTE } \\
\text { INFILTRATION } \\
\mathbf{n}(\%)\end{array}$ \\
\hline $\mathbf{1}$ & $10(100 \%)$ & $10(100 \%)$ & $10(100 \%)$ & $2(20 \%)$ & - \\
$\mathbf{2}$ & $8(80 \%)$ & $8(80 \%)$ & $8(80 \%)$ & $10(100 \%)$ & - \\
\hline
\end{tabular}

Group 1 -gastric devascularization and removal of the liver after $3 \mathrm{~h}$. Group 2 -gastric devascularization and removal of the liver after $6 \mathrm{~h}$. Group 3 -gastric devascularization and removal of the liver after $12 \mathrm{~h}$.

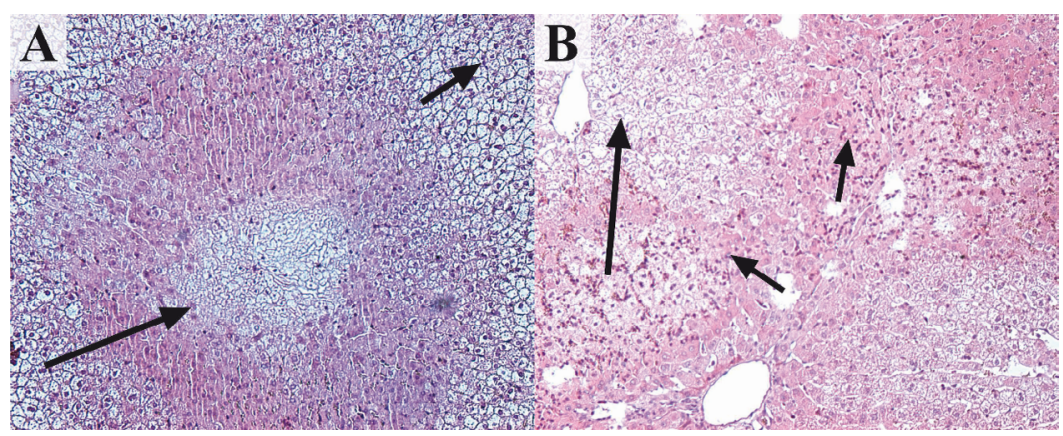

Figure 4 - Microscopic aspect of livers removed after gastric ischemia. A. Center lobule necrosis (big arrow) and vacuolar hydropic degeneration (small arrow) in a rabbit liver from group 1 (HE, $\times 100)$. B. Areas of necrosis (big arrow) and leukocytes infiltration (small arrows) in a rabbit liver from group 3 (HE, x100).

\section{Biochemical analyses}

Table 2 shows the ALP, AST, ALT, GGT, TP and bilirubins values dosed in the animals from groups 1,2 , and 3 . Comparing the preand post-gastric ischemia in each group, an increase in ALT in group $2(p=0.0444)$ and in group 3 ( $p=0.0154)$ was identified. In group 1 , the values of this enzyme did not differ ( $p=$ $0.085)$. No variation was observed in the values of AST in Group 1 and Group 2 ( $p>0,05)$, but they were higher after gastric ischemia in Group $3(p=0,0198)$. A reduction in TP was observed in Group 1 ( $p=0.0014)$, Group 2 ( $p=0.0063)$, and Group 3 ( $p=0.0038)$. The albumin values diminished after gastric ischemia in Group 1 ( $p=0.0018)$, Group $2(p=0.0158)$ and group $3(p=0.0162)$. The values of direct bilirubin diminished after gastric ischemia in group $1(p$ $=0.0098)$ and increased in group $3(p=0.0190)$, remaining unchanged in group $2(p=0.1396)$. The values of indirect bilirubin increased after gastric ischemia in Group $2(p=0.0494)$, but remained unchanged in Group $1(p=0.4796)$ and Group $3(p=0.1345)$. No variation was observed in the ALP and GGT values after gastric ischemia in the three groups $(p>0.05)$, although there was great increases of these values in some animals of Group 3. 
Table 2 - Values (mean \pm standard error from the mean) of ALT, AST, ALP, GGT, TP, albumin, direct and indirect bilirubin, of animals from groups 1, 2 and 3, obtained before and after determined periods of gastric ischemia.

\begin{tabular}{|c|c|c|c|c|}
\hline VARIABLES & GROUPS & PREOPERATIVE & POST-ISCHEMIA & PRE- AND POST-VARIATION \\
\hline \multirow{3}{*}{$\begin{array}{c}\text { ALT } \\
(I U / I)\end{array}$} & 1 & $135.8 \pm 23.2 \mathrm{~A}$ & $158.8 \pm 19.8 \mathbf{A}$ & $23.00 a$ \\
\hline & 2 & $115.6 \pm 16.0 \mathrm{~A}$ & $151.0 \pm 46.2 \mathrm{~B}$ & $35.40 \mathrm{a}$ \\
\hline & 3 & $96.8 \pm 20.0 \mathrm{~A}$ & $135.0 \pm 45.6 \mathrm{~B}$ & $-61.80 b$ \\
\hline \multirow{3}{*}{$\begin{array}{l}\text { AST } \\
\text { (IU/I) }\end{array}$} & 1 & $32.4 \pm 12.5 \mathrm{~A}$ & $20.2 \pm 12.5 \mathrm{~A}$ & $-12.20 \mathrm{a}$ \\
\hline & 2 & $40.2 \pm 6.3 \mathrm{~A}$ & $138.0 \pm 264.0 \mathrm{~A}$ & $93.80 \mathrm{a}$ \\
\hline & 3 & $44.8 \pm 10.6 \mathrm{~A}$ & $776.2 \pm 320.4$ B & 731.40 a \\
\hline \multirow{3}{*}{$\begin{array}{c}\text { ALP } \\
(I U / I)\end{array}$} & 1 & $99.4 \pm 23.6 \mathrm{~A}$ & $104.8 \pm 25.9 \mathrm{~A}$ & $5.40 \mathrm{a}$ \\
\hline & 2 & $141.6 \pm 44.2 \mathrm{~A}$ & $138.0 \pm 21.5 \mathrm{~A}$ & $-3.60 a$ \\
\hline & 3 & $146.0 \pm 41.6 \mathrm{~A}$ & $290.0 \pm 194.2 \mathrm{~A}$ & 144.00 a \\
\hline \multirow{3}{*}{$\begin{array}{c}\text { GGT } \\
(I U / I)\end{array}$} & 1 & $5.9 \pm 4.8 \mathrm{~A}$ & $6.4 \pm 3.6 \mathrm{~A}$ & $0.50 \mathrm{a}$ \\
\hline & 2 & $5.4 \pm 2.2 \mathrm{~A}$ & $5.9 \pm 2.0 \mathrm{~A}$ & $0.54 \mathrm{a}$ \\
\hline & 3 & $5.2 \pm 2.9 \mathrm{~A}$ & $17.6 \pm 13.4 \mathrm{~A}$ & $12.26 \mathrm{a}$ \\
\hline \multirow{3}{*}{$\begin{array}{c}\text { TP } \\
(\mathrm{g} / \mathrm{dl})\end{array}$} & 1 & $8.6 \pm 0.8 \mathrm{~A}$ & $6.8 \pm 0.3 \mathrm{~B}$ & $-1.60 a$ \\
\hline & 2 & $7.3 \pm 0.5 \mathrm{~A}$ & $6.4 \pm 0.3 \mathrm{~B}$ & $-1.00 a$ \\
\hline & 3 & $7.0 \pm 0.5 \mathrm{~A}$ & $5.6 \pm 0.4 \mathrm{~B}$ & $-1.40 a$ \\
\hline \multirow{3}{*}{$\begin{array}{l}\text { ALBUMIN } \\
(\mathrm{g} / \mathrm{dl})\end{array}$} & 1 & $4.2 \pm 0.2 \mathrm{~A}$ & $3.3 \pm 0.4 \mathrm{~B}$ & $-0.90 a$ \\
\hline & 2 & $3.7 \pm 0.2 \mathrm{~A}$ & $2.5 \pm 0.3 \mathrm{~B}$ & $-1.22 \mathrm{a}$ \\
\hline & 3 & $3.7 \pm 0.9 \mathrm{~A}$ & $2.4 \pm 0.5 \mathrm{~B}$ & $-1.28 a$ \\
\hline \multirow{3}{*}{$\begin{array}{l}\text { DIRECT BILIRUBIN } \\
(\mathrm{mg} / \mathrm{dl})\end{array}$} & 1 & $0.26 \pm 0.1 \mathrm{~A}$ & $0.2 \pm 0.1 \mathrm{~B}$ & $-0.05 a$ \\
\hline & 2 & $0.5 \pm 0.3 \mathrm{~A}$ & $0.6 \pm 0.4 \mathrm{~A}$ & $0.10 a b$ \\
\hline & 3 & $0.2 \pm 0.03 \mathrm{~A}$ & $0.3 \pm 0.1 \mathrm{~B}$ & $0.16 \mathrm{~b}$ \\
\hline INDIRECT & 1 & $0.5 \pm 0.2 \mathrm{~A}$ & $0.5 \pm 0.3 \mathbf{A}$ & $-0.01 \mathbf{a}$ \\
\hline \multirow{2}{*}{$\begin{array}{l}\text { BILIRUBIN } \\
(\mathrm{mg} / \mathrm{dl})\end{array}$} & 2 & $1.0 \pm 0.8 \mathbf{A}$ & $1.3 \pm 0.6 \mathrm{~B}$ & $0.03 a$ \\
\hline & 3 & $0.9 \pm 0.4 \mathrm{~A}$ & $1.9 \pm 1.5 \mathrm{~A}$ & $1.06 \mathrm{a}$ \\
\hline
\end{tabular}

Group 1 -gastric devascularization and removal of the liver after 3h. Group 2-gastric devascularization and removal of the liver after $6 \mathrm{~h}$. Group 3 -gastric devascularization and removal of the liver after $12 \mathrm{~h}$. ALT - alanine aminotransferase. AST - aspartate aminotransferase. ALP - alcaline phosphatase. GGT - gamaglutamiltranspeptidase. TP - total proteins. $a, b$ - Same column: equal letter $p>0.05$, and different letters $p<0.05$. A, B - Same line: equal letter $p>0.05$, and different letters $p<0.05$

\section{Discussion}

The effects of gastric devascularization on the vitality of the stomach have been evaluated in few experimental studies ${ }^{3,4}$. In humans, partial stomach devascularization is used in the treatment of hypertension of gastric varices, acute hemorrhagic lesions of the gastroduodenal mucosa and also can be observed in cases of venous thrombosis, phlebitis and coagulopathies are predisposing factors of ischemia ${ }^{4}$.

In this study, devascularization was performed in the entire wall of the stomach, including all veins and arteries. The results obtained showed that the model of gastric ischemia was effective in all animals, as confirmed by macro- and microscopic 
examination, which revealed varied degrees of necrosis of the gastric wall. Gastric ischemia, even when induced for a relatively short period of time, may cause severe and irreversible injuries to one or more different tissues of the stomach.

As observed, the gastric fundus and body were the regions more sensitive to ischemia, wheras the antrum was preserved in practically all animals. Since all the vessels of the greater and lesser curvatures were sectioned, the most likely explanation for the preservation of the antropyloric region is based on two possibilities. The first refers to the rich vascular anastomosis present in the gastroduodenal interface. These anastomosis derive from small branches of the gastroduodenal artery, which derives from the hepatic artery and are largely responsible for the formation of the vascular plexuses present in the submucosa of the more distal regions of the stomach. Submucosal microvessels originating from the duodenum probably provide supplementary blood irrigation to the gastric antrum, leading to a greater resistance to ischemia.

Although there was a greater resistance of antrum region to ischemia, it was possible do confirm that desvascularization of stomach, even for a short period of time, result in a severe hemorrhagic necrosis of the gastric fundus and body wall, which was confirmed in the macro and microscopic studies.

The present work studied the repercussions of gastric ischemia upon the liver. The model of necrosis used here was chosen due to the systemic complications resulting from gastric ischemia, a subject which is scarce in the literature. The devascularization of the stomach was carried out near the stomach wall, taking care not to affect the vascularization of neighboring organs, which can interfere in post-operative results.

Gastric ischemia, such as the gut ischemia, unleashes a distributive shock due to the increase in the vascular permeability and reduction in aorta blood flow ${ }^{9}$ and a local inflammatory process which extends to other organs and can be prolonged, giving rise to the onset of MODS $^{10}$. Liver failure is a common complication in critical diseases and contributes to the worsening of patient prognosis ${ }^{10-15}$. The liver plays an important role in the immune, endocrine, and metabolic control, and is frequently damaged in medical conditions of shock, sepsis and systemic inflammation. Changes in perfusion and hepatic cellular homeostasis stemming from these situations interfere in their functions and determine local and systemic deleterious effects $^{7}$. The present work showed that the desvascularization of stomah resulted in liver damage. Based on the results of this study, it is worth to suppose that ischemia of the stomach is associated with hepatic dysfunction, which is defined as an increase in the circulating levels of aminotransferases and bilirubins ${ }^{11}$. Since the increase in ALT, AST and bilirubins was not related to other comorbidities that could interfere in the results, it is possible to presume that the liver damage was secondary to gastric ischemia. The increase of direct bilirubin observed in Group 3 was probably caused by the vacuolization occurred in these animals, which may result in obstruction of biliary capillaries. In the other hand, the increased values of indirect bilirubin observed in Group 2 is commonly caused by hemolysis and hepatic dysfunction, which results from deformation of red blood cells and hypoxemia during systemic inflammation (SIRS) ${ }^{11}$. Although the values of inflammatory mediators were not measured in this work, it is possible to suggest, based on literature and on the results of this study, that gastric ischemia unleashes a local and systemic inflammatory process. The reduction in the albumin values in the animals from the three groups reinforces the SIRS hypothesis, in which an increase in protein consumption 
occurs $^{5,11}$. During SIRS, the albumin values can diminish in up to $70 \%$, due to the vasodilation and hepatic prioritization for the syte-phase proteins $^{8,12}$. No increase was observed in the values of other hepatic markers, probably due to the short period of observation of the animals. A pilot study showed that the rabbits died between 12 and 24 hours after ligature and sectioning of the gastric vasculature. For this reason, this study favored to evaluate the animals over a shorter period of time, in an attempt to verify the initial changes taking place in the liver. The first signs of liver failure result from the hypoperfusion of splanchnic organs $^{12}$, which leads to an increase in the circulating values of hepatic markers, such as aminotransferases and bilirubins ${ }^{11}$. By contrast, secondary hepatic dysfunction, which is more severe than primary one, is characterized by structural and functional lesions, and results from the direct action of bacteria, endotoxins and inflammatory molecules, which unleash or perpetuate the systemic inflammation and organic dysfunction ${ }^{11}$. Gastric ischemia causes a distributive shock, with a reduction in the splanchnic perfusion, which compromises the proper functions of the organ ${ }^{12,16}$. Diverse mechanisms are involved in the pathogenesis of this disorder, including the deformation of red blood cells, as well as an increase in both vascular permeability and the apoptosis of endothelial cells. Change in the vasomotor tone is also observed, with an opening of the arteriovenous derivations, as well as an increase in platelet and leukocyte aggregation, due to the greater expression of adhesion molecules on the surface of the endothelial cells ${ }^{17}$. The activation of coagulation cascade results in deposit of fibrin and formation of microthrombi ${ }^{17,18}$. All of these mechanisms act together, causing tissue hypoxia, as well as the degeneration and death of hepatocytes ${ }^{11}$, which may better explain the morphological changes in the present study, characterized by vacuolar hydropic degeneration and hepatocellular necrosis. Trauma, shock, and systemic inflammation result in the activation of the immune system, promoting a greater production and release of inflammatory mediators, such as interleukins (IL) 1, 6, and 10; inflammatory proteins; and tumor necrosis factor (TNF). These mediators act directly in the hepatic parenchyma, causing the degeneration and death of hepatocytes ${ }^{19}$. In addition, IL1 and TNF, associated with the vascular changes and platelets and leukocytes aggregation may be related to the hepatic cells necrosis, which contributes to accelerated hepatic dysfunction ${ }^{14,15,20,21}$. Kupffer cells, macrophages present in the liver, are highlighted the main causes of direct lesions to this organ ${ }^{15,21}$. These are the first line of defense against microorganisms that cross the intestinal mucosa and reach the blood vessels ${ }^{6}$. These cells possess a large amount of inflammatory mediators, such as TNF, IL1, E2 prostaglandin, superoxides, and nitric oxide (NO) ${ }^{21,22}$, which are released in response to inflammation, infection, and changes in hepatic oxygenation ${ }^{8}$. These products provoke hepatic morphological and functional changes ${ }^{11}$, worsening hypoperfusion lesions ${ }^{23}$. Hepatic endothelial cells (HEC) can also contribute to the formation of hepatic damage during the systemic inflammatory response. Although they consist of a barrier between the sinusoidal capillaries and the hepatic parenchyma, once activated by the inflammatory mediators, the $\mathrm{HEC}$ release IL8 and the platelets aggregation factor (PAF), which stimulates the adherence of the platelets and leukocytes to the hepatic parenchyma ${ }^{6,14,23}$, perpetuating the hepatocellular lesion process ${ }^{11,23-26}$. This fact can be explained by the leukocyte infiltration observed in the rabbits' livers after 12 hours of gastric ischemia. Previous literature has shown hepatic morphological and functional effects secondary to SIRS and ischemia of 
other organs. Singer et al. ${ }^{17}$ observed platelet and leukocyte adhesion in rat livers two hours after the induction of sepsis. Dourado et al. ${ }^{27}$ observed an increase in the levels of AST, ALT and inflammatory cytokines after gut ischemia/ reperfusion. Brøchner et al. ${ }^{28}$ reported liver failure coupled with the presence of leukocyte infiltration in mice livers after the induction of renal ischemia. In a similar study, Seifi et al. ${ }^{29}$ reported liver failure after renal ischemia and reperfusion (I/R), while Kadkhodaee et al. ${ }^{19}$ verified hepatic dysfunction associated with leukocyte infiltrate, as well as congestion, degeneration and necrosis in rat livers after 60 minutes of renal I/R. In another model of systemic inflammation, Mohammad et al. ${ }^{30}$ induced ischemia of the posterior limbs by occlusion of femoral artery for two hours, followed by reperfusion for 24 hours. This procedure led to an increase in ALT and AST, sinusoidal congestion, enlarged sinusoids, cytoplasmic vacuolation and necrosis. The results of the present study are in accordance with the data from literature, once hepatic dysfunction, degeneration and hepatocellular necrosis, associated with leukocyte infiltrate in the parenchyma after 12 hours of gastric ischemia, were observed.

These results demonstrated that gastric ischemia caused changes in liver morphology and function. With three hours ischemia, the magnitude of these changes was less than those with 12 hours. These findings confirm the importance of prompt diagnoses and treatment in medical conditions of gastric ischemia, to prevent remote lesions. This study was the first in the literature to indicate hepatic lesions resulting from gastric ischemia and necrosis.

\section{Conclusion}

Gastric ischemia and necrosis is associated with liver structure and functions damages.

\section{References}

1. Becker S, Bonderup OK, Fonslet TO. Ischaemic gastric ulceration with endoscopic healing after revascularization. Eur J Gastroenterol Hepatol. 2006;18(4):451-4. PMID: 16538121.

2. Tang SJ, Daram SR, Wu R, Bhaijee F. Pathogenesis, diagnosis, and management of gastric ischemia. Clin Gastroenterol Hepatol. 2014;12(2):246-52. doi: 10.1016/j. cgh.2013.07.025.

3. Magalhães $M A B$, Petroianu A, Figueiredo JA, Alberti LR, Barbosa AJA. Greater resistance of the rabbit antropyloric region to experimental acute gastric ischemia. J Bras Patol Med Lab. 2013;49(4):278-82. doi: 10.1590/S1676-24442013000400009.

4. Magalhães $M A B$, Barbosa AJA, Figueiredo JA, Alberti LR, Petroianu A. Effects of different periods of gastric ischaemia in the viability of the tissue of body, fundus and antrum region of rabbit stomach. ABCD Arq Bras Cir Dig. 2015;8(3) 53-6. doi: 10.1590/ S0102-67202015nahead00001.

5. Bauer M, Press AT, Trauner M. The liver in sepsis: patterns of response and injury. Curr Opin Crit Care. 2013;19(2):123-7. doi: 10.1097/MCC.0b013e32835eba6d.

6. Antoniades CG, Berry PA, Wendon JA, Vergani $D$. The importance of immune dysfunction in determining outcome in acute liver failure. J Hepatol. 2008;49(5):845-61. doi: 10.1016/j. jhep.2008.08.009.

7. Bakker PJ, Scantlebery AM, Butter LM, Claessen N , Teske GJD, van der Poll T, Florquin S, Leemans JC. TLR9 mediates remote liver injury following severe renal ischemia reperfusion. PLoS One. 2015;10(9):e0137511. doi: 10.1371/journal. pone.0137511.

8. Lelubre C, Vincent JL. Mechanisms and treatment of organ failure in sepsis. Nat Rev Nephrol. 2018;14(7):417-27. doi: 10.1038/ s41581-018-0005-7.

9. Cerqueira NF; Hussni CA; Yoshida WB; Padovan CR. Systemic evaluation on ischemia and reperfusion injury of splanchnic organs in rats. Acta Cir Bras. 2009;24(4):290-5. doi: 10.1590/S0102-86502009000400008.

10.CarcilloJA, Podd B, Aneja R, WeissSL, HallMW, Cornell TT, Shanley TP, Doughty LA, Nguyen TC. Pathophysiology of pediatric multiple 
organ dysfunction syndrome. Pediatr Crit Care Med. 2017;18(3 Suppl 1):S32-45. doi: 10.1097/PCC.0000000000001052.

11.Spapen H. Liver perfusion in sepsis, septic shock, and multiorgan failure. Anat Record. 2008;291(6):714-20. doi: 10.1002/ar.20646.

12. Ribeiro ME, Sequeira J, Trinca LA, Yoshida WB. Effect of protective solutions and hydroxyethyl starch in the attenuation of the injuries of ischemia and reperfusion of splanchnic organs. Acta Cir Bras. 2015;30(6):407-13. doi: 10.1590/S0102865020150060000006.

13. Yang R, Tenhunen J, Tonnessen TI. HMGB1 and histones play a significant role in inducing systemic inflammation and multiple organ dysfunctions in severe acute pancreatitis. Int J Inflam. 2017; 2017:1817564. doi: $10.1155 / 2017 / 1817564$.

14.McDonald B, Jenne CN, Zhuo L, Kimata $K$, Kubes P. Kupffer cells and activation of endothelial TLR4 coordinate neutrophil adhesion within liver sinusoids during endotoxemia. Am J Physiol Gastrointest Liver Physiol. 2013;305(11):G797-806. doi: 10.1152/ajpgi.00058.2013.

15. Hekimoglu AT, Toprak GT, Akkoc $H$, Evliyaoglu O, Ozekinci S, Kelle I. Oxytocin ameliorates remote liver injury induced by renal ischemia-reperfusion in rats. Korean $\mathrm{J}$ Physiol Pharmacol. 2013;17(2):169-73. doi: 10.4196/kjpp.2013.17.2.169.

16.Beltran NE, Sacristan E. Gastrointestinal ischemia monitoring through impedance spectroscopy as a tool for the management of the critically ill. Exp Biol Med (Maywood). 2015;240(7):835-45. PMID: 25711880.

17.Singer $G$, Urakami $H$, Specian RD, Stokes KY, Granger DN. Platelet recruitment in the murine hepatic microvasculature during experimental sepsis: role of neutrophils. Microcirculation. 2006;13(2):89-97. PMID: 16459322.

18.Samuels JM, Moore HB, Moore EE. Coagulopathy in severe sepsis: interconnectivity of coagulation and the immune system. Surg Infect (Larchmt). 2018;19(2):208-15. doi: 10.1089/ sur.2017.260.

19.Kadkhodaee M, Golab F, Zahmatkesh M, Ghaznavi R, Hedayati M, Arab AH, Ostad SN, Soleimani M. Effects of different period of renal ischemia on liver as a remote organ.
World J Gastroenterol. 2009;15(9):1113-8. PMID: 19266605.

20.Sakurai K, Miyashita T, Okazaki M, Yamaguchi T, Ohbatake Y, Nakanuma S, Okamoto K, Sakai S, Kinoshita J, Makino I, Nakamura K, Hayashi H, Oyama K, Tajima H, Takamura H, Ninomiya I, Fushida S, Harada K, Harmon JW, Ohta T. Role for neutrophil extracellular traps (NETs) and platelet aggregation in early sepsis-induced hepatic dysfunction. In Vivo. 2017;31(6):1051-8. doi: 10.21873/ invivo.11169.

21.McDonald B, Jenne CN, Zhuo L, Kimata $K$, Kubes P. Kupffer cells and activation of endothelial TLR4 coordinate neutrophil adhesion within liver sinusoids during endotoxemia. Am J Physiol Gastrointest Liver Physiol. 2013;305(11):G797-806. doi: 10.1152/ajpgi.00058.2013.

22. Kielar ML, RohanJeyarajah D, Lu CY. The regulation of ischemic acute renal failure by extrarenal organs. Curr Opin Nephrol Hypertens. 2002;11(4):451-7. PMID: 12105397.

23.Lapchak PH, Kannan L, Ioannou A, Rani P, Karian P, Lucca JJD, Tsokos GC. Platelets orchestrate remote tissue damage after mesenteric ischemia-reperfusion. Am J Physiol Gastrointest Liver Physiol. 2012;302(8):G888-97. doi: org/10.1152/ ajpgi.00499.2011.

24.Croner RS, Hoerer E, Kulu Y, Hackert T, Gebhard MM, Herfarth C, Klar E. Hepatic platelet and leukocyte adherence during endotoxemia. Crit Care. 2006;10(1):R15. PMID: 16420661.

25. Horie $\mathrm{Y}$, Ishii H. Liver dysfunction elicited by gut ischemia-reperfusion. Pathophysiology. 2001;8(1):11-20. PMID: 11476968.

26.Zarbock A, Ley K. Mechanisms and consequences of neutrophil interaction with the endothelium. Am J Pathol. 2008;172(1):1-7. PMID: 18079440.

27.Fernandes de Mattos Dourado S, Barbeiro DF, Koike MK, Barbeiro HV, Pinheiro da Silva F, César Machado MC. Diazoxide reduces local and remote organ damage in a rat model of intestinal ischemia reperfusion. J Surg Res. 2018;225:118-24. doi: 10.1016/j. jss.2018.01.009.

28.Brøchner AC, Dagnaes-Hansen F, HøjbergHolm J, Toft $P$. The inflammatory response in blood and in remote organs following acute 
kidney injury. APMIS. 2014;122(5):399-404. doi: 10.1111/apm.12157.

29.Seifi B, Kadkhodaee M, Najafi A, Mahmoudi A. Protection of liver as a remote organ after renal ischemia-reperfusion injury by renal ischemic postconditioning. Int J Nephrol. 2014;2014:120391. PMID: 24744919.
30. Mohammad AT, Gholamreza J, Amirali J, Amir S, Omidreza SA, Amin A. Effects of $\mathrm{N}$-acetylcysteine on liver remote injury after skeletal muscle ischemia reperfusion in rats. Turk J Gastroenterol. 2014;25(1):43-7. doi: 10.5152/tjg.2014.6008.

\section{Correspondence:}

Andy Petroianu

Avenida Afonso Pena, 1626/1901

30.130-100 Belo Horizonte - MG Brasil

Tel.: (55 31)98884-9192 / 3409-9948

petroian@gmail.com

Received: July 19, 2018

Review: Sept 15, 2018

Accepted: Oct 16, 2018
Conflict of interest: none

Financial sources: CNPq, and FAPEMIG
${ }^{1}$ Research performed at Laboratory of Experimental Surgery, Department of Surgery, Faculty of Medicine, Universidade Federal de Minas Gerais (UFMG), Belo Horizonte-MG, Brazil. 